\title{
TRANSPOSED SUPERNUMERARY PREMOLAR IN ALIGNMENT - A CASE REPORT
}

Ngeow WC. Transposed supernumery premolar in alignment - a case report. Annals Dent Univ Malaya 1996; 3: 69-72

\begin{abstract}
Supernumerary premolars have been reported to occur in $0.29 \%$ of the general population and to represent about $9.1 \%$ of all supernumerary teeth. Most of the supernumerary teeth reported in the literature were detected by radiographs as most of them were unerupted or impacted. A search of the literature revealed not many cases of fully erupted and well aligned supernumerary premolars being reported. A case of a unilateral transposed supernumery premolar that had erupted into alignment is presented here. The remarkable feature of this case is that the supernumery premolar is transposed between the first and second permanent maxillary molars. The etiology of supernumerary teeth is also reviewed.
\end{abstract}

Key Words: alignment, premolar. supernumerary, supplemental, transposition.

\author{
Wei Cheong Ngeow. BDS (Mal) \\ Tutor, \\ Faculty of Dentistry, \\ University of Malaya, \\ 59100, Kuala Lumpur, \\ Malaysia.
Address of correspondence:
Wei Cheong Ngeow,
Faculty of Dentistry,
University of Malaya,
59100, Kuala Lumpur,
Malaysia.

\section{Introduction}

Supernumerary teeth have been found in all of the toothbearing areas of the dental arches and may occur in the primary or permanent dentition ${ }^{(1)}$. The prevalence of supernumeraries in the deciduous dentition has been reported to be $0.8 \%{ }^{(2)}$ and that in the permanent dentition as between $0.3 \%$ and $3.5 \% \%^{(3,4,5)}$. Supernumerary teeth have a greater predilection for certain areas. The majority of supernumerary teeth occur in the maxilla with $90 \%$ located in the premaxillary region. This is followed by the mandibular premolar and maxillary molar region ${ }^{(5,6,7,8)}$, and more rarely, in the canine region ${ }^{(9)}$.

Supernumerary teeth can be classified according to their morphology. Various morphogical types have been described: supplemental (or eumorphic), rudimentary (conical), tuberculate, or molariform. A supernumerary tooth that is similar morphologically and structurally to a member of the normal dentition is referred to as a supplemental tooth.

The embyronic origin of these is not clearly understood. A relationship to genetic patterns of inheritance has not been established, although there is a 2:1 male to female ratio(10).

Supernumerary premolars have been reported to occur in $0.29 \%$ of the general population and to represent about $9 . .1 \%^{(6)}$ of all supernumerary teeth. They are more likely to develop in the mandible than in the maxilla ${ }^{(11)}$. Multiple supernumerary premolars are slightly rarer than single occurrence. Only two subjects had been reported to have more than two supernumeraries in a study by Bodin and co-workers ${ }^{(8)}$. The highest number of supernumerary premolars mentioned in a single person was eleven teeth ${ }^{(12)}$. Supernumerary maxillary premolars have variable morphology and they are predominantly conical ${ }^{(10)}$. Those in the mandible usually mimic the shape of a normal premolar crown (supplemental).

A number of well known conditions predispose to supernumerary teeth. These include Cleidocranial Dysostosis, Gardner's syndrome and cleft lip and palate ${ }^{(10)}$.
Besides, there is a condition termed "Non-syndrome multiple supernumerary teeth"(12) in which no associated systemic conditions is detected. Most of the supernumerary teeth occur in the mandible ${ }^{(12)}$

Most literature reported the occurrences of supernumerary premolars as being detected radiographically in surveys or during routine orthodontics treatment $t^{(2,5}$ 11). The majority of these supernumerary premolars were unerupted or impacted beneath the natural dentition. They were also of the disfiguring or ectopic varieties, erupting buccal or lingual to the natural dentition. They were also the disfiguring or ectopic varieties, erupting buccal or lingual to the natural dentition. Not many reports on erupted supernumerary premolars in occlusion or in alignment could be found in the literature $(13,14,15,16)$.

On occasion, the normal or supernumerary teeth may erupt into an inappropriate position. This pattern of abnormal eruption is called dental transposition. A misplaced tooth may be confused with a supernumerary tooth because of transposition. This article reports on a case of an aligned supplemental premolar distal to the maxillary left first molar. It is a genuine dental transposition case.

\section{CASE REPORT}

A healthy 24-year-old Indian male Medical student was seen in a private dental clinic with a request for routine dental check-up.

Oral hygiene was good and no new or recurrent caries was detected. However, it was discovered that he had an extra fully erupted premolar on the maxillary left quadrant (Figure 1). When asked about the supernumerary premolar, the patient did not notice any abnormality about his dentition.

The supernumerary premolar was of the size of a normal maxillary premolar and was located between the maxillary left first and second molar. It was well aligned in the maxillary left buccal segment.

Generally, the patient had skeletal pattern Class I. He 


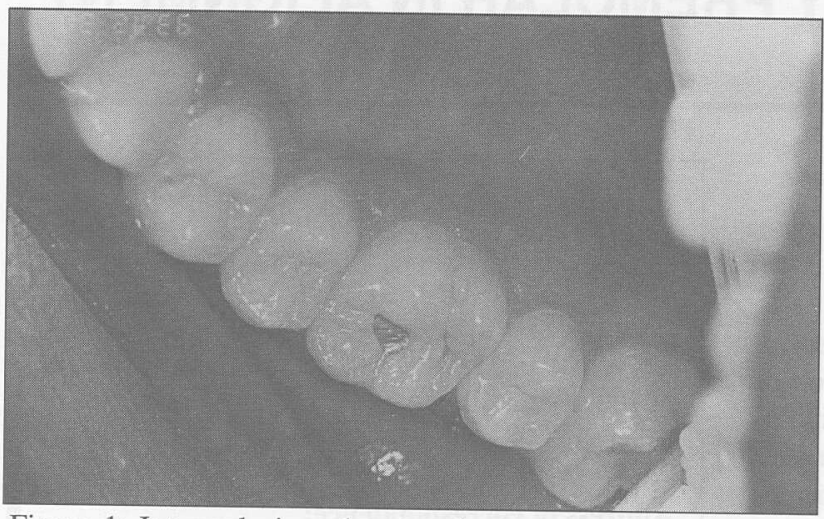

Figure 1: Intraoral view showing the transposed supplemental premolar in alignment between the maxillary molars.

had competent lips and the ratio of his facial height was within normal range. His incisors were also of Class I relationship with overjet of $2 \mathrm{~mm}$ and overbite of $30 \%$. However, there was a midline shift of the upper central incisors of about $1 \mathrm{~mm}$ to the right. There was mild maxillary anterior teeth crowding.

The patient was not aware of any family member who had supernumerary teeth. However, no relatives were available for examination. The patient was only given oral hygiene instruction. He was also informed of the supplemental tooth that was transposed and was in alignment. There appears to be no reason for extraction of the supplemental premolar.

No radiographic examination was taken initially and when it was decided to present this case, the patient could not be contacted for further radiographic examination.

\section{DISCUSSION}

Supernumerary premolars, especially in the maxillas, are unusual occurrences and third premolars which erupt without undue disturbance of the dental arch alignment are very rare indeed. Supplemental premolars transposed and erupted into occlusion are not frequently reported in the literature ${ }^{(13,14,15,16)}$. Most reported cases of supernumerary maxillary premolars were of the disfiguring or ectopic varieties, erupting buccal or lingual to the natural dentition.

Jasmin, Jonesco-Benaiche and Muller-Giamarchi( ${ }^{(17)}$ presented a case of supernumerary mandibular third premolar in a pair of twins. It is interesting to note that the pantomographic examination revealed a mirrorimaging of three mandibular supernumerary premolars in both children ${ }^{(17)}$.

(Lowry and MacCallum(18), Fuller ${ }^{(19)}$ and Lin ${ }^{(20)}$ reported cases with supplemental teeth distal to the maxillary first permanent molars which were displaced buccally and not in occlussion. Barnett ${ }^{(21)}$ reported a case with supernumerary premolars between the first and second molars which was erupted buccally in the maxilla and lingually in the mandible. In addition, Van de Voorde $^{(22)}$ reported four fully erupted supernumerary left mandibular premolars and three similar right premolars which were in reasonably good alignment and which were in occlusion with a partial denture in the upper arch.
Vijayavergia and associates ${ }^{(13)}$ were the first to report a case of transposed supernumerary premolar in occlusion with natural dentition. Their case was two bilaterally functioning supernumerary premolars located distal to the permanent maxillary first molars. Their patient came with a complaint of pain at the maxillary right second and third molars. Barker ${ }^{(14)}$ reported a similar occurrence and coined the nomenclature transposed third premolars in occlusion. A year later, Raphael ${ }^{(15)}$ reported the third case of such occurrence. The patient was, however, symptom free.

Means and Tabeling ${ }^{(16)}$ were the first to report a case of a unilateral transposed supernumerary premolar in occlusion. In their report, the patient complainted of pain on the right retromolar pad region. They found that the patient had a supernumerary premolar in satisfactory occlusion between the right maxillary first and second molar. The second molar was, however, supraerupted and impinging on the retromolar pad during maximum closure.

Most teeth erupted in their expected position in the dental arch. On rare occasions however, a tooth may be reversed in its site of eruption (such as a canine between two premolars). This transposed tooth may be misdiagnosed as a supernumerary tooth. Orthodontic treatment is not indicated to correct the transposition. The use of tooth masking procedures may the treatment of choice.

Seventy-five percent of supernumerary premolars are unerupted $^{(11)}$ and usually asymptomatic. However, in the review of cases of transposed supernumerary premolar, two cases had signs and symptoms caused by the additional teeth onto the dentition which led to the discovery of the teeth ${ }^{(13,16)}$. The patient reported here was symptom free and he was expected to remain so, provided he maintained his good oral hygiene.

The aetiology of supernumerary teeth has not yet been completely clarified. Various theories have been suggested to explain this phenomenon ${ }^{(23)}$. They are:

a) Atavism or reversion

b) Heredity

c) Aberrations during embryologic formation

d) Progress zone

e) Unified etiologic explanation.

\section{a) Atavism or reversion}

This hypothesis proposes a reversion to an ancestral human dentition which contained a larger number of teeth $^{(1,24)}$. It has been proposed that a supernumerary premolar may be an atavistic reappearance of the extra premolar of the primitive dentition. However, this theory is not probable because if atavism is responsible, both the maxilla and mandible should be equally affected.

\section{b) Heredity}

Supernumerary teeth is theorirised to result from mutant genes. This is supported by the observation of a greater frequency of supernumerary teeth in patients with maxillofacial anomalies such as Cleidocranial Dysostosis ${ }^{(25)}$, cleft lip or cleft palate ${ }^{(26)}$, 
Fabry's disease (angiokeratoma corporis diffusum)(27) and Gardner's syndrome ${ }^{(28)}$. It has also been proposed that autosomal inharitence with lack of penetration might also give rise to supernumerary teeth ${ }^{(29)}$. The greater frequency of supernumerary teeth in male than in female indicates the possibility of a sex-linked heredity ${ }^{(30)}$.

c) Aberrations during embryologic formation.

There are several theories which are based on aberrations during embryologic formation. They include theory of epithelial remnants ${ }^{(31)}$, theory of supernumerary dental germs, theory of duplication by dichotomy of tooth germs, theory of additional proliferation of the dental lamina ${ }^{(32)}$, theory of the Prague school ${ }^{(33)}$, the Godo theory ${ }^{(34)}$, and the theory of histochemical disruption ${ }^{(35)}$.

\section{d) Progress zone}

This theory proposed that supernumerary teeth result from the progress zone of the dental lamina in the end of every tooth series or class ${ }^{(36)}$.

\section{e) Unified etiologic explanation}

This theory suggests a unified aetiology for anomalies of tooth number and size $\mathrm{s}^{(37)}$. It is based on a multifactorial model that has a continuous scale with thresholds related to a spectrum of tooth number and size. The position of the anomaly is determined by a combination of genetic and environmental factors. This model is based on experimental results in which it successfully explains the presence of supernumerary teeth and other anomalies.

Oehlers suggested that supplemental premolars were formed from an extension of the dental lamina in the region ${ }^{(38)}$. He cited that the accessory buds may possibly represent members of a "post permanent dentition". Price and Hoggins found that in general, the development of supernumerary occurred about seven to ten years after development of the premolar teeth of normal series ${ }^{(39)}$. They also suggest that these teeth may belong to a post permanent dentition. Formation from extension of the dental lamina is a possible aetiology for this case and it could very well have been due to a post permanent dentition.

Supernumerary teeth usually cause dental abnormalities except in cases of deeply buried asymptomatic teeth. These teeth should be reviewed periodically.

The most common consequences of unerupted supernumerary teeth are delayed eruption, noneruption or malposition of the permanent teeth. Spacing with persistence in the region in question is an indication of the probable existence of a supernumerary tooth. Supernumerary teeth may also cause root resorption or it may give rise to cystic lesion. Tendency towards formation of cyst was suggested by Poyton and Morgan as characteristic of mandibular supernumerary premolars ${ }^{(40)}$.

When supernumerary teeth and transposed teeth are erupted but not in alignment, they can cause displacement of the adjacent teeth with crowding enchancing various types of malocclusion. The adjacent teeth may be tipped, rotated or in infraocclusion. This may cause trauma to the surrounding structures. Generally, they may also cause difficulty in function like disturbing speech and chewing. The transposed supplemental premolar presented here somehow only caused mild anterior crowding. Otherwise, the patient was asymptomatic. Recurrence is not unknown. Poyton and Morgan ${ }^{(38)}$ reported a case of postmature development of supernumerary premolars in which three impacted mandibular supernumerary premolars in an 11 yearold girl which were removed in September, 1944 were found to have recurred five years later. Such incidence has not been reported in maxillary supernumerary premolars.

In conclusion, this case report illustrates that a transposed supplemental tooth need not disturb the patient's occlusion and function. Such case should be leftt alone.

\section{Acknowledgement}

The author wishes to thank Dr. Kok Kew Tan for the suggestion and permission to report the case above. Also grateful thanks to Dr. Sarah Haniza for her critical review of the manuscript.

\section{References}

1) Burzynski NJ. Escobar VH. Classification and genetics of numeric anomalies of dentition. Birth Defects Original Articles Series 1983; $19: 95-106$

2) Brook AHN. Dental anomalies of number, form and size: Their prevalence in British school chilldren. J Int Assoc Dent Child 1974; 5 : 37-53

3) Nazif MM, Ruffalo RC, Zullo T. Impacted supernumerary teeth: a survey of 50 cases. J Am Dent Assoc 1983; $106: 201-4$

4) Primosch RE. Anterior supernumerary teeth-assessment and surgical intervention in children. Pediatr Dent $1981 ; 3$ : 204-13

5) Parry RR, Iyer VS. Supernumerary teeth amongst orthodontic patients in India. Br. Dent J 1961; 111:257-8

6) Grahnen H, Lindahl B. Supernumerary teeth in the permanent dentition: a frequency study. Odontol Rev 1961; $12: 290-4$

7) Bodin I., Julin P, Thomsson M. Frequency and distribution of supernumerary teeth among 21,609 patients. 
Dentomaxillofac Radiol 1978; 7: 15-7

8) Bodin I., Julin P, Thomsson M. Hyperdontia : IV. Supernumerary premolars. Dentomaxillofac Radiol 1981; 10: 99-103.

9) Davis PJ. Hypodontia and hyperdontia of permanent teeth in Hong Kong school children. Community Dent Oral Epidemiol 1987; 15:218-20

10) Breckon JJ, Jones SP. Late forming supernumeraries in the mandibular premolar region. Br J Orthodont 1991; 18:329-31.

11) Stafne EC. Supernumerary teeth. Dent Cosmos 1932; 74: 653-9

12) Yusof WZ. Non syndrome multiple supernumerary teeth: Literature review. Canadian Dent Assoc J 1990; 56: 1479

13) Vijayavergia NK, Dayal PK, Joshi MR. Bilateral functioning premolar-form supernumerary teeth distal to the maxillary permanent first molars. J Dent 1977; 5: 76-8

14) Barker BCW. Transposed third premolars in occlusion. Oral Surg 1977; 44: 165

15) Raphael DM. Transposed supernumerary premolar. Oral Surg 1978; 46: 598

16) Means DA, Tabeling JJ. Transposed supernumerary premolar in occlusion. Oral Surg Oral Med Oral Pathol 1984; 58: 367

17) Jasmin JR, Jonesco-Benaiche N, Muller-Giamarchi M. Supernumerary teeth in twins. Oral Surg Oral Med Oral Pathol 1993; 76: 258-9

18) Lowry JC. MacCallum HR. Bilateral supernumerary teeth in the maxillary molar region. Br Dent J 1965; 118;3901

19) Fuller AC. Supernumerary teeth. Report of bilateral maxillary supernumerary. Br Dent J 1966; 121: 340

20) Lin TY. Seven supernumerary premolars. Report of case Br Dent J 1967; 123: 437-8

21) Barnett BS. A case of multiple supernumerary teeth. Br J Orthod 1974; 1: 217-8

22) Van de Voorde HE. Functioning supernumerary mandibular premolars. Report of case. Dent Dig. 1971; 77: 392-5

23) Grimanis GA, Kyriakides AT, Spyropoulus ND. A survey on supernumerary molars. Quintessence International 1991; 22: 989-95

24) Cardiner JH. Supernumery teeth. Dent Practit 1961; 12: 63-73

25) Angelopoulos AP. In Textbook of Oral Pathology (in Greek). Medical Publications Litsas. Athens. 1976; pg163

26) Millhon JA, Stafne EC. Incidence of supernumerary and congenitally missing lateral incisor teeth in 81 cases of harelip and cleft palate. Am J Orthod 1941; 37: 599-604

27) Regattieri LR. Parker JL. Supernumerary teeth associated with Fabry-Anderson's syndrome. Oral Surg Oral Med Oral Pathol 1973; 35: 432-3

28) Zvolanek JW, Spotts TM. Supernumerary mandibular premolars, report of cases. J Am Dent Assoc 1985; 110: $721-3$

29) Sedano HO, Gorlin RJ. Familial occurrence of mesiodens. Opt Acta 1969; 27: 360-1

30) Bruning LJ, Dunlap L, Mergele ME. Report of supernumerary teeth in Houston Texas school children. J Dent Child 1957; 24: 98-105

31) Fisher SE. Maxillary sixth molars. Br Dent J 1982; 152: 356

32) Fluery JE, Deboets D, Assaud C. et al. Molaires surnumeraires. Rev Stomatol Chir Maxillofac 1984: 85: 136-41

33) Mezl T. Genese et classification des anomalies du evelopment dentaire, d'apres I'ecole de Prague. Rev Stomatol Chir Maxillofac 1948; 49: 97-103

34) Godo T. Contributions a I'Etude des Germes Supplementaires. Paris, 1954. Thesis

35) Tessier HM. Considerations anatomocliniques sur les 4es Molaires. Marseille, 1954. Thesis

36) Schwartz JH. Supernumerary teeth in anthropoid primates and models of tooth development. Arch Oral Biol 1984; 29: $833-7$

37) Brook AH. A unifying etiological explanation for anomalies of human tooth number and size. Arch Oral Biol 1984; 29: 373-8

38) Oehlers FAC. Postpermanent premolars. Br Dent J 1952; 93: 157-8

39) Price C, Hoggins GS. A category of supernumerary premolar teeth. Br Dent J 1969; 126: 224-8

40) Poyton GH, Morgan GA, Crouch SA. Recurring supernumerary mandibulars. Report of a case of Postmature Development. Oral Surg Oral Med Oral Pathol 1960; 13: 964-6 